\title{
Басс H.B. \\ Оптимальные подходы в обучении студентов чтению и деталированию сборочных чертежей
}

Брянский государственный технический университет (Россия, Брянск)

doi: $10.18411 / \mathrm{j}-05-2021-219$

\section{Аннотация}

Рассмотрены особенности обучения студентов чтению и деталированию сборочных чертежей на занятиях по инженерной графике в вузе. Предложена последовательность изложения учебного материала. Разобраны этапы чтения и деталирования сборочного чертежа. Показаны ошибки, наиболее часто встречающиеся при изучении темы. Представлен вариант задания и пример выполнения учебной работы.

Ключевые слова: сборочный чертеж, чертеж общего вида, чтение сборочного чертежа, деталирование, согласование размеров.

Abstract

The specifics of teaching students to read and detail an assembly drawing in engineering drawing classes at the university are considered. The sequence of presenting the teaching material is suggested. The stages of reading and detailing an assembly drawing are explained. The most common errors encountered in the course of learning the topic are provided. A task variant and an example of training task execution are presented.

Keywords: assembly drawing, general arrangement drawing, reading an assembly drawing, detailing, coordination of dimensions.

Формирование приемов чтения сборочных чертежей и выполнение их деталирования имеет большое учебное значение. В ходе изучения темы у студентов развивается умение выявлять конструктивную форму деталей, входящих в сборочную единицу, совершенствуются навыки выполнения чертежей оригинальных деталей; развивается умение самостоятельно пользоваться справочными материалами.

Прочитать сборочный чертеж - значит создать пространственный образ объекта; получить сведения о размерах, способах обработки и сборки элементов объекта; определить назначение, устройство, принцип работы изделия; выяснить взаимодействие, способы соединения и форму каждой детали [2].

В учебной практике чтение сборочного чертежа помогает развить и закрепить знания и умения, приобретенные при выполнении проекционных чертежей. Чтение сборочных чертежей намного сложнее чтения чертежей деталей. Сборочный чертеж выполняется с применением большего количества условностей, условных знаков и надписей. Без знания этих условностей читать сборочный чертеж невозможно. Из сказанного следует, что обучение чтению сборочных чертежей является сложной задачей.

Обучение чтению чертежей деталей должно вестись на протяжении всего курса, начиная с первого раздела. При изучении разделов курса характер заданий на чтение чертежей должен постепенно усложняться. В период изучения проекционного черчения и технического рисования следует осваивать основную задачу чтения чертежей - понимание пространственных образов по чертежу. При изучении машиностроительных и строительных чертежей осваивают чтение условностей, а также продолжают тренировать восприятие по чертежу сложных пространственных форм деталей, узлов и сооружений. 
При чтении сборочных чертежей рекомендуют следующую последовательность:

1. Ознакомление с изделием. Выясняют наименование сборочной единицы; читают масштаб чертежа; выявляют главные размеры узла; знакомятся с описанием узла.

2. Чтение изображений. Определяют, какие виды, разрезы, сечения даны на чертеже и каково назначение каждого изображения; выясняют положения секущих плоскостей.

3. Изучение составляющих частей изделия. Читают спецификацию и выясняют наименования отдельных деталей, входящих в узел; по чертежу определяют форму, взаимное положение и назначение деталей; изучают составные части изделия по порядку номеров позиций в спецификации.

4. Изучение конструкции изделия. Выясняют характер соединения отдельных деталей между собой; для неразъемных соединений определяют каждый элемент и места их соединения; для разъемных соединений выявляют все крепежные детали; при наличии подвижных соединений устанавливают, какие детали перемещаются и по каким поверхностям происходит их сопряжение с другими деталями.

5. Определение последовательности сборки и разборки изделия. Читают имеющиеся на чертеже указания о технологии сборки и разборки [6].

Для успешного чтения следует рекомендовать студентам рассматривать проекции сборочного чертежа одновременно. Разбор чертежа начинают с главного вида, как наиболее характерного и имеющего большую часть порядковых номеров деталей.

В случае затруднений в нахождении проекций детали рекомендуют предварительно найти проекции более простых соседних деталей.

Для того чтобы научить студентов пользоваться спецификацией, необходимо задавать вопросы о материале деталей, количестве болтов, винтов и т.п., о том, какого типа шпонка показана на чертеже, и др.

Следует уделить внимание вопросам о типах резьб, об основных размерах зубчатых колес, о типах подшипников, видах передач и др.

Обучение чтению сборочных чертежей нужно начинать с фронтального разбора сборочного чертежа с использованием учебного плаката. В ходе разбора устанавливают последовательность и методику чтения чертежа.

Необходимо обратить внимание на следующие моменты:

- Рассматривая виды соединения деталей, характер их движения, конструкцию и устройство изделия, обучаемые должны четко видеть границы между отдельными смежными деталями в сборочном чертеже. Для этого необходимо указать, что штриховка на разрезах одной и той же детали имеет одно и то же направление и расстояния между линиями штриховки равны.

- Большое внимание следует уделять выявлению формы деталей, входящих в сборочную единицу. С этой целью рекомендуется предложить обучаемым обвести деталь по контуру, считая, что других деталей в сборке нет [5].

Далее идет разбор чертежей на местах в индивидуальном порядке. Целесообразно дать студентам 10-15 минут для ознакомления с чертежом, а затем побеседовать с каждым, предлагая ответить на вопросы.

После того как студенты освоятся с методикой чтения сборочных чертежей, им выдается задание на деталирование, которое заключается в выполнении рабочих чертежей деталей сборочной единицы. Чтение и деталирование чертежей тесно связаны между собой. В учебном процессе деталирование используется как один из методов приобретения глубоких знаний и навыков чтения чертежей. 
Рабочие чертежи деталей составляются на основе чертежей общих видов технического проекта изделия. В учебных условиях, по существу, не разграничивают чертеж общего вида и сборочный чертеж, так как сборочные чертежи дополняют некоторыми изображениями, позволяющими выявить форму всех оригинальных деталей и характер их соединений.

Деталирование выполняют по следующим этапам:

1. Изучают сборочную единицу, прочитав её чертеж (последовательность указана ранее), особенно обратив внимание на форму деталей, их назначение и взаимодействие.

2. Устанавливают детали, чертежи которых необходимо выполнить. Деталирование начинают с простейших по форме деталей. Выделяют стандартные и прочие изделия, на которые не составляют рабочих чертежей.

3. Находят и анализируют имеющиеся на чертеже изображения намеченной детали, определяют ее главное изображение, количество и состав необходимых изображений. Количество изображений должно быть минимальным, но достаточным для полного представления формы и размеров детали. Следует отметить, что количество и состав изображений детали на рабочем чертеже могут не соответствовать изображениям на чертеже сборочной единицы. При выборе положения для главного изображения детали также нельзя копировать ее положение на сборочном чертеже.

4. Выбирают масштаб изображений. При этом не обязательно придерживаться одного и того же масштаба для всех деталей.

5. Выбирают нужный формат листа бумаги, наносят рамку, основную надпись.

6. Компонуют и последовательно выполняют изображения. На чертеже детали изображают и те её элементы, которые на сборочном чертеже не показаны или показаны упрощенно (фаски, галтели, проточки и др.). Размеры этих конструктивных элементов определяют не по сборочному чертежу, а по соответствующим стандартам.

Наносят на чертеж размеры, обозначения шероховатости поверхности и другие данные. Если на сборочном чертеже указывают лишь основные размеры, то на чертеже детали нужно проставлять все размеры, которые необходимы для её изготовления.

Размеры пазов для шпонок, размеры резьбовых изделий и т.п. должны быть выбраны и нанесены в соответствии с данными справочников.

Рекомендуется тщательно проверить размеры деталей, сопрягающихся между собой; отметить сопрягаемые поверхности деталей, то есть те, которые взаимодействуют с поверхностями других деталей.

Для сопрягающихся поверхностей нужно согласовать размеры. Другими словами, одинаковыми должны быть, например, номинальный размер диаметра отверстия в зубчатом колесе и номинальный наружный размер вала в передаче. К сопрягаемым поверхностям предъявляют повышенные требования в отношении точности обработки и шероховатости.

7. Проверяют чертеж и окончательно его оформляют: заполняют основную надпись (часть данных берут из спецификации), при необходимости указывают технические требования [1].

В учебной практике при деталировании чертежей сборочных единиц для определения размеров деталей применяют пропорциональный (угловой) масштаб. Он представляет собой прямоугольный треугольник, отношение катетов которого равно отношению длин соответствующих отрезков на изображении и в натуре.

Следует указать, что, выполняя деталировку, надо каждую деталь вычерчивать на отдельном формате. 
Необходимо обратить внимание на наиболее частые ошибки, которые допускают студенты при деталировании:

- К числу типичных ошибок можно отнести: пропуск линии видимого и невидимого контуров, неправильное и незаконченное выполнение разрезов и сечений, пропуски центровых и осевых линий, неверные обозначения изображений.

- Ошибкой является копирование изображений детали со сборочного чертежа. Иногда следует изменить количество и характер изображений, чтобы показать конструктивные особенности детали.

- Обучаемые неправильно изображают резьбу и резьбовые соединения, пропускают части конструкции или неправильно выявляют форму деталей (пропускают отверстия, пазы и т.п.), деформируют конструкцию детали или её части, присоединяют части других деталей к изображаемой.

Достаточно трудно представить все особенности детали, особенно если она скрыта изображением другой, расположенной ближе к наблюдателю.

В этом случае студентам приходится опираться не столько на зрительное восприятие, сколько на умение логически рассуждать в процессе анализа чертежа. Следует учить обучаемых отвлекаться от многих линий и мысленно восстанавливать изображение детали.

Рекомендуют для деталирования предлагать преимущественно интересные в проекционном отношении детали. Возможно выполнение обучаемыми аксонометрических изображений, что обеспечит полное чтение чертежа.

Необходимо предлагать студентам задания на деталирование, требующие вдумчивой работы и творческих усилий. Вариативность предлагаемых заданий (сложность, объем работы и др.) зависит от направления подготовки студентов (то есть от реализуемых компетенций обучения), а так же времени, заложенном в учебной программе дисциплины. Исследователи данной проблемы предлагают обширный перечень заданий по чтению и деталированию сборочного чертежа [4].

Далее представлен один из вариантов учебного задания по данной теме (рис. 1), которое предлагается студентам на кафедре начертательной геометрии и графики БГТУ по альбому С.К. Боголюбова [3].
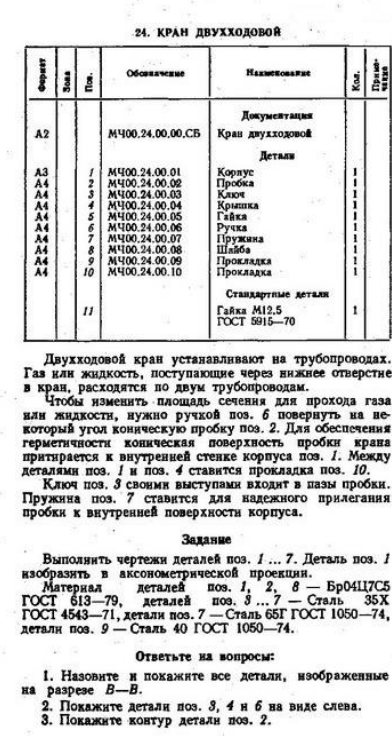

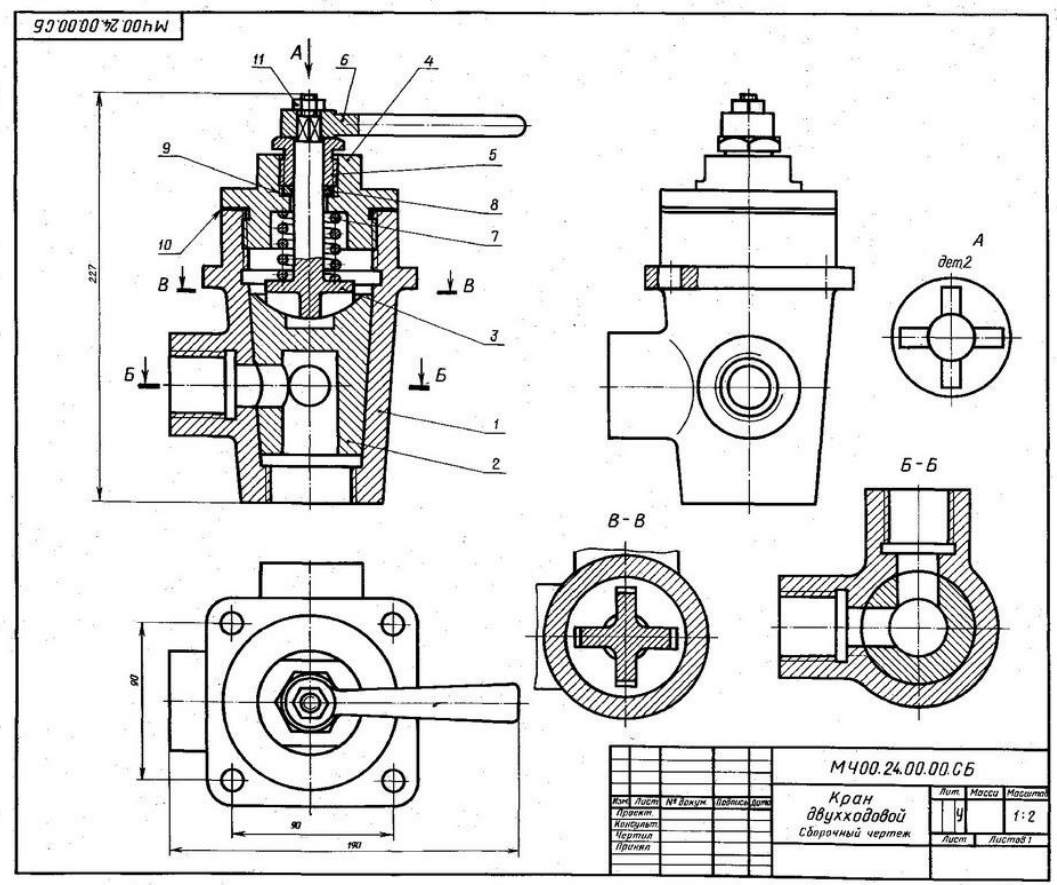

Рис. 1. Задание на чтение и деталирование сборочного чертежа 
Каждый студент получает чертеж сборочной единицы и описание к нему. Необходимо прочитать чертеж, ответив на вопросы. Затем выполнить эскизы оригинальных деталей и создать по ним электронные модели. Собрать 3D-модель сборочной единицы и выполнить ассоциативный чертеж, создать спецификацию. На рис. 2, 3 приведены фрагменты выполнения учебной графической работы.

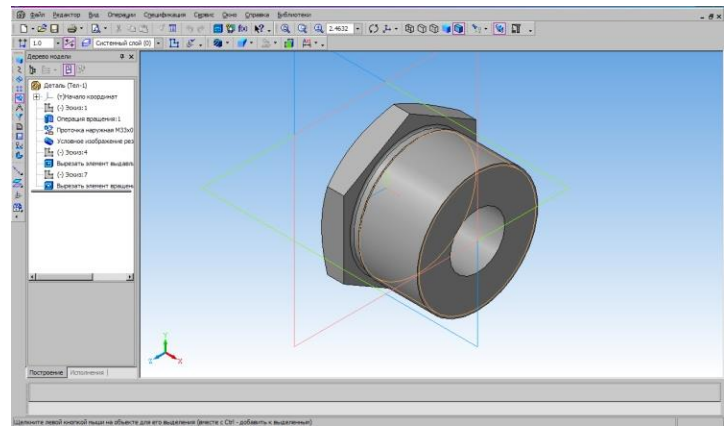

a)

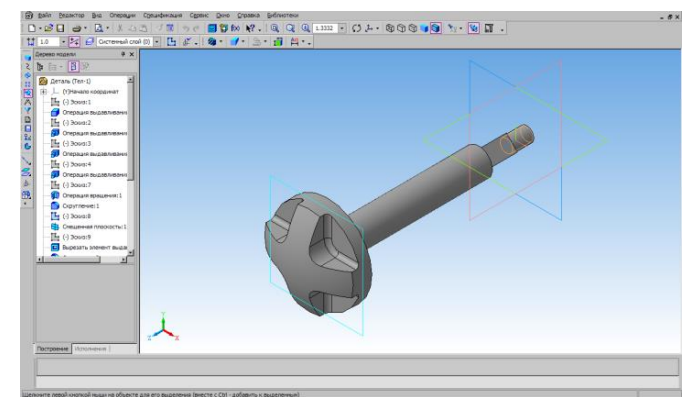

в)

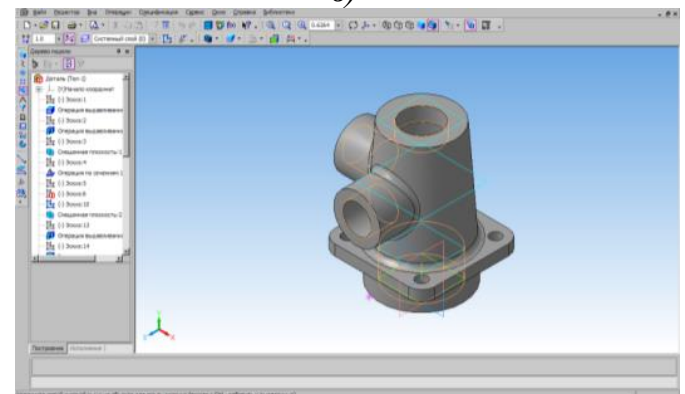

d)

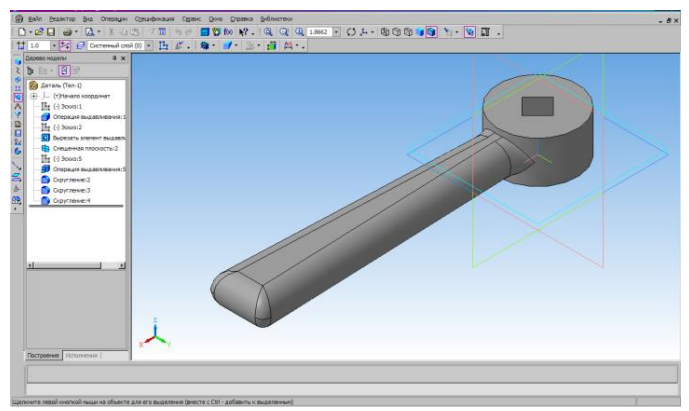

б)

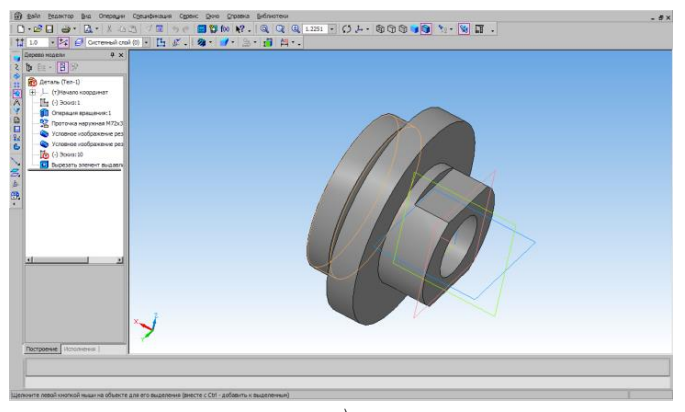

2)

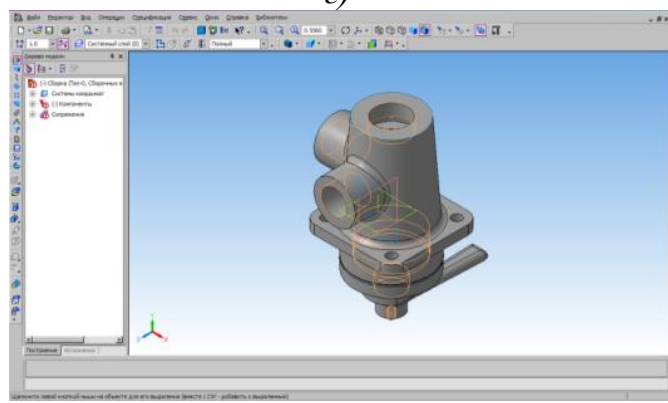

e)

Рис. 2. Фрагмент учебной графической работь:

a, 6, 6, г, д-3D-модели оригинальных деталей (наиболее интересной формы), $e-3 D$-модель сборочной единиць

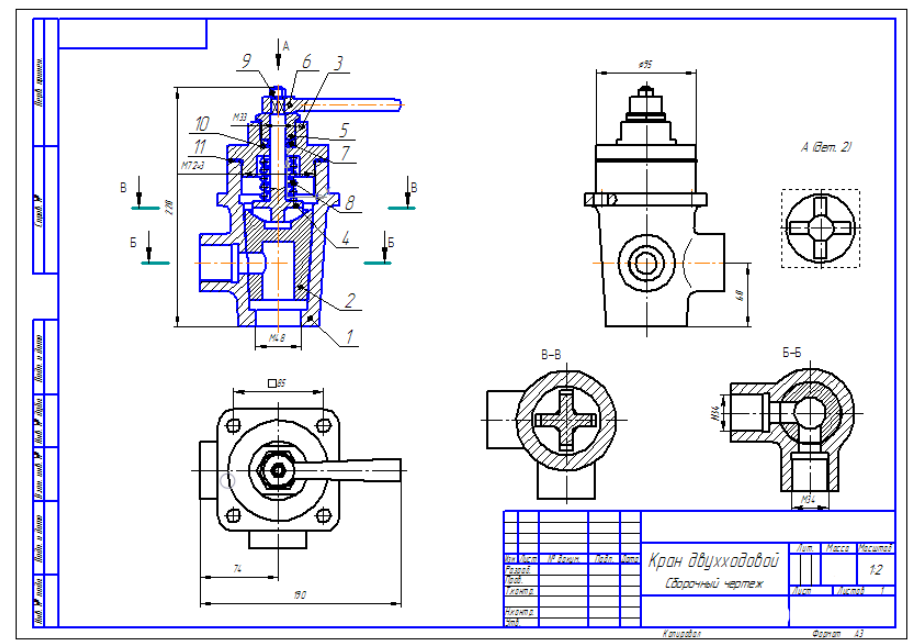

a) 


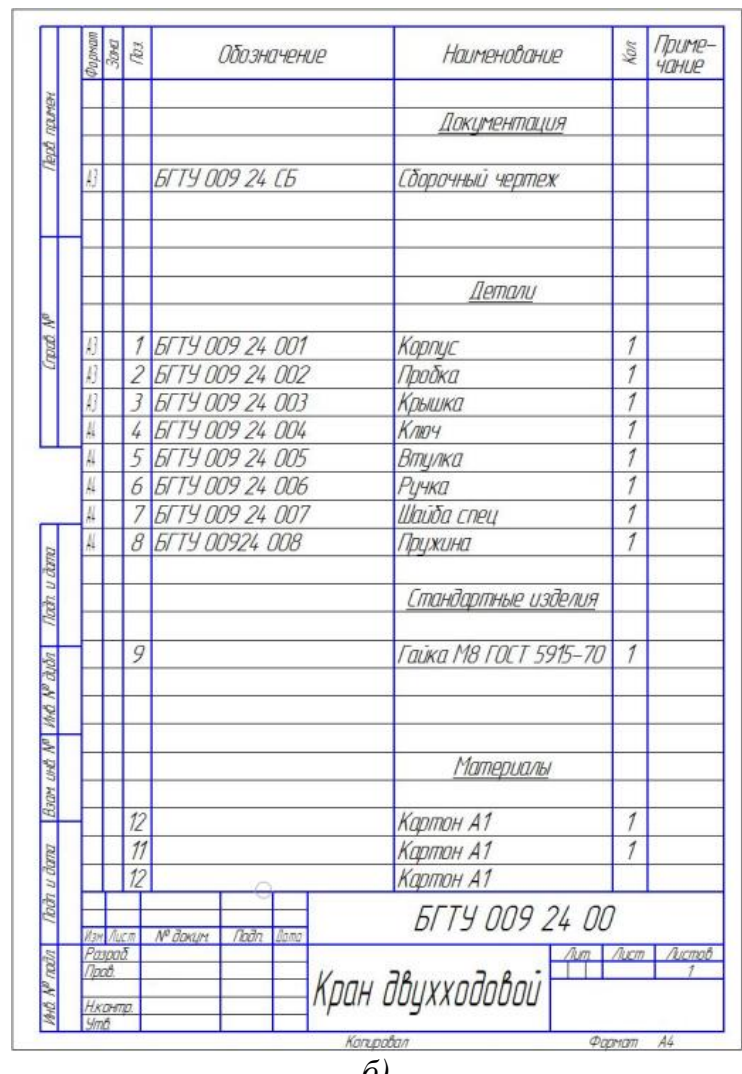

б)

Рис. 3. Фрагмент графической работы: $a$ - чертеж сборочной единищы, б - спецификация

Успешной реализации подходов при изучении темы «Чтение и деталирование сборочных чертежей» безусловно способствует методическое обеспечение учебного процесса. На кафедре начертательной геометрии и графики БГТУ разработаны учебное пособие [1], методические рекомендации для студентов и преподавателей по наиболее сложным вопросам, учебные плакаты и презентации, собраны альбомы сборочных единиц.

Задание на чтение и деталирование сборочного чертежа, как правило, завершает курс обучения инженерной графике. По результатам его выполнения можно с уверенностью сказать насколько хорошо обучаемые знают материал по всему курсу, грамотно читают и выполняют чертежи деталей и сборочных единиц. Таким образом, оптимально подобранные преподавателем содержание, методы и средства позволят достичь необходимого результата в обучении студентов чтению и деталированию сборочных чертежей.

$$
\text { *** }
$$

1. Афонина, Е.В. Деталирование чертежей сборочных и общих видов: учеб. пособие / Е.В. Афонина, В.Н. Ожерельев. - Брянск: БГТУ, 2016. - 68 с. - ISBN 978-5-89838-909-3.

2. Афонина, Е.В. Инженерная графика с элементами проектной деятельности: учеб. пособие / Е.В. Афонина, Н.В. Басс. - Брянск: БГТУ, 2021. - 108 с. - ISBN 978-5-907271-84-5.

3. Боголюбов, С.К. Чтение и деталирование сборочных чертежей: Альбом: учеб. пособие / С.К. Боголюбов.-3-е изд., перераб. - Москва: Машиностроение, 1996. - 88 с.

4. Кирпичникова, Н.Н. Вариативность выполнения заданий по сборочному чертежу / Н.Н. Кирпичникова, В.В. Никольский // Символ науки. - 2017. - № 03-2. - С. 97-101. URL: https://cyberleninka.ru/article/n/variativnost-vypolneniya-zadaniy-po-sborochnomu-chertezhu/viewer (дата обращения: 15.04.2021).

5. Розов, С.В. Руководство к преподаванию черчения / С.В. Розов. - Изд. 2-е, перераб. и доп. Москва: Машиностроение, 1968. - 376с.

6. Черчение: учеб. пособие для студентов худож.-граф. фак. пед. ин-тов / Д.М. Борисов [и др.]; под общ. ред. Д.М. Борисова. - Москва: Просвещение, 1980. - 352 с. 